\title{
Survey on Handoff with QoS in WIMAX
}

\author{
Mamta Chauhan \\ M.tech CSE \\ Thakral College Of Technology \\ Bhopal (M.P),India
}

\author{
Rajneesh Choubey \\ Prof ,CSE Department \\ Thakral College Of Technology \\ Bhopal (M.P) , India
}

\author{
Roopali Soni \\ Prof of CSE, Head of Dept \\ Thakral College Of Technology \\ Bhopal (M.P), India
}

\begin{abstract}
Wimax stands for worldwide interoperability for microwave access. Wimax Technology that enables ubiquitous delivery of the wireless broadband service for fixed and/or for mobile users . wimax is wireless digital communication system also known as 802.16 . which is intended for wireless " Metropolitan area networks ". The challenge for Broadband Wireless Access networks is in provides the quality of service (QoS) simultaneously to services with very different characteristics. QoS support in wireless networks is a much more difficult task than in wired networks, mainly because the characteristics of a wireless link are highly variable and unpredictable, both on a time-dependent basis and a location dependent basis. A special requirement for mobile device is ability to change the serving BS, if there exists another BS , for example better link quality to reach of MS . we consider an interworking architecture of wireless mesh backbone and propose an effective vertical handoff scheme between 802.11 and 802.16 wireless access networks. The proposed reducing handoff signaling overhead on the wireless backbone and providing a low handoff delay to mobile nodes.
\end{abstract}

While handoff a mechanism to maintain uninterrupted user communication session during a user movements from one location to another. Wimax supports for various types off handoff to maintain communication .

\section{Keywords}

Wimax , handover, wifi , ipv6, QoS , WMR ,WLAN ,ertPS , nrtPS , B.E, UGS ,FA ,HA ,DHCP, PWMR , NWMR , COA .

\section{INTRODUCTION}

The IEEE standard has 802.16 i.e the working group creates a new standard commonly known as the wimax. It is for the broadband wireless access at high speed at low cost on the telecommunication technology. The intend of ieee 802.16 is to providing the wireless access over the long distances in a diversity of ways from point to point links to full mobile cellular types access as shown in fig. it covers the metropolitan area networks of several kilometers and is also called the wireless man . wimax base stations can offer greater wireless coverage of about 5 of miles, with the LOS ( line of sight ) transmission within the bandwidth of upto 70 mbps .if we analyze theoretically the range of the wimax base station for broadband for wireless access in range upto 30 miles $(50 \mathrm{~km}$ ) for fixed stations . and 3 to 10 miles ( 5 to 15 $\mathrm{km}$ ) for mobile stations with the maximum data rates up to 70 mbps . IEEE 802.16 standards group has been developing a set of standards for broadband ( high speed ) wireless access in metropolitan area. It contain some numerous optional features and mechanism. The worldwide interoperability for the microwave access forum or the wimax forum is a group of 400 plus networking equipment vendors .
IEEE 802.16 and WiMAX are designed as a complimentary technology to $\mathrm{Wi}-\mathrm{Fi}$ and Bluetooth. The following table provides a comparison of 802.16 with to 802.11 (WLAN) and 802.15.1 (Bluetooth): In addition to single hop IEEE 802.16 PMP (point to multipoint ) operation . IEEE 802.16 standard basically defined the basic signaling flows and message formats to establish a mesh network connection . subsequent ally the mesh mode specifications were integrated into the IEEE 802.16 -2004 revision.

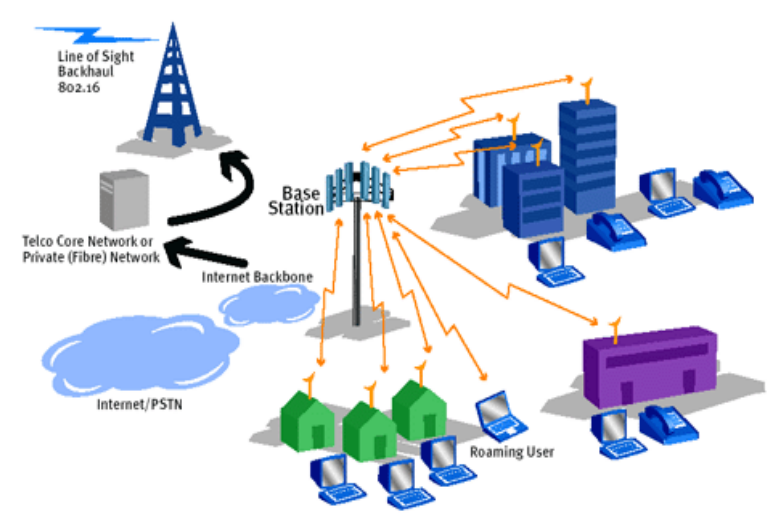

Fig 1. Wimax Metropolitan Area Network

backhaul deployment and reconfigurability of various deployment scenarios include the citywide wireless coverage , backhaul is for connecting the $3 \mathrm{G} \mathrm{RNC}$ with base stations and others. Although single hop wimax provides high flexibility to attain a quality of service in terms of data throughput, achieving the same in multihop wimax mesh challenging . one of the major difficulty is dealing with the interference from transmission of the neighboring wimax nodes .

\section{TABLE I}

Comaparision between various IEEE Standards of Wireless network

\begin{tabular}{|c|c|c|c|c|}
\hline Parameters & $\begin{array}{l}\text { IEEE802.16d } \\
(802.16-2004 \\
\text { Fixed } \\
\text { WiMAX })\end{array}$ & $\begin{array}{l}\text { IEEE802.16e } \\
(802.16-2005 \\
\text { Mobile } \\
\text { WiMAX) }\end{array}$ & $\begin{array}{l}802.11 \\
\text { (WLAN) }\end{array}$ & $\begin{array}{l}\text { 802.15.1 } \\
\text { (Bluetooth) }\end{array}$ \\
\hline $\begin{array}{l}\text { Frequency } \\
\text { Band: }\end{array}$ & $2-66 \mathrm{GHz}$ & $2-11 \mathrm{GHz}$ & \begin{tabular}{|l|}
$2.4-$ \\
$5.8 \mathrm{GHz}$
\end{tabular} & $2.4 \mathrm{GHz}$ \\
\hline
\end{tabular}




\begin{tabular}{|l|l|l|l|l|}
\cline { 2 - 3 } & $\sim 31$ miles & $\sim 31$ miles & $\begin{array}{l}\sim 100 \\
\text { meters }\end{array}$ & $\sim$ 10meters \\
\hline $\begin{array}{l}\text { Maximum } \\
\text { Data rate: }\end{array}$ & $\sim 134$ Mbps & $\sim 75 \mathrm{Mbps}$ & $\begin{array}{l}\sim 55 \\
\text { Mbps }\end{array}$ & $\sim 3 \mathrm{Mbps}$ \\
\hline $\begin{array}{l}\text { Number of } \\
\text { users: }\end{array}$ & Thousands & Thousands & Dozens & Dozens \\
\hline
\end{tabular}

\section{KEY FEATURES OF WIMAX NETWORK}

The various key features of WiMAX networks that distinguish it from the other metropolitan area wireless access technologies are : 1. Its use the OFDMA (Orthogonal Frequency Division Multiple Access ), 2. Scalable use of the spectrum width (i.e varying from 1. $25 \mathrm{Mega} \mathrm{Hz}$ to $28 \mathrm{Mega}$ $\mathrm{Hz}$ ), 3. Time and Frequency Division Duplexing (TDD and FDD), 4. Advanced antenna procedures such as the beam forming, Multiple Input Multiple Output (MIMO), 5. Per subscriber adaptive modulation, 6. Advanced coding procedures such as space-time coding and turbo coding, 7. Strong security and 8. Multiple QoS classes appropriate not only for voice but designed for the combination of data, voice and the video services. In terms of assured services, WiMAX includes several Quality of Service (QoS) mechanisms at the MAC (Media Access Control) layer. Typically, the QoS support in wireless networks is much more challenging than that in wired networks because the characteristics of the wireless link are highly variable and unpredictable both on a time-dependent basis and a location dependent basis. With the longer distance, multipath $\&$ fading effects are also put into the consideration. The Request/Grant method is used for mobile stations (MSs) to access the media with a centralized control at base stations (BSs). WiMAX is a connectionoriented technology (with 16 bits connection identifier or CID shared for downlink and uplink). Therefore, MSs are not allowed to access the wireless media unless they register and request the bandwidth allocations from the BS first except for certain time slots reserved specifically for contention-based access.

The 802.16 standard specifies two modes for sharing the wireless medium: point-to-multipoint (PMP) and mesh (optional). With PMP, the BS serves a set of SSs within the similar antenna sector in a broadcast way, with all SSs receiving the same transmission from the BS. Transmissions from SSs are directed to and centrally coordinated by the BS (Base station ). On the other hand, in the mesh mode, the traffic can be routed through other SSs and can occur directly among SSs( Service stations). Access coordination is distributed among the SSs. The PMP operational mode fits a typical fixed BWA scenario, where multiple types of service subscribers are served by one centralized service provider so that they can be access external networks (e.g., the use of Internet) or services like (e.g., Digital Video Broadcasting DVB). In this reading we focus on the PMP mode. In PMP (point to multi point ) mode, uplink (from SS to BS) and downlink (from BS to SS) data transmissions occur in separate time frames. In the downlink sub frame, the BS transmits a burst of MAC protocol data units (PDUs). While the transmission is broadcast, all SSs listen to the data transmitted by the BS. However, an SS is only required to

process PDUs that are addressed to itself or that are explicitly intended for all the SSs. The MAC protocol is connectionoriented: all data communications, for both transport and control, are in the context of a unidirectional connection. At the start of each frame, the BS schedules uplink \& downlink grants in order to meet the negotiated QoS requirements. Each SS learns the boundaries of its allocation with Wn the current uplink subframe by decoding the UL-MAP message. In different way the DL-MAP message contains the timetable of the downlink grants in the forthcoming downlink subframe.

\section{DIFFERENT CLASSES OF WIMAX QUALITY OF SERVICES}

IEEE 802.16 defines five QoS service classes: Unsolicited Grant Scheme (UGS), Extended Real Time Polling Service (ertPS), Real Time Polling Service (rtPS), Non Real Time Polling Service (nrtPS) and Best Effort Service (BE). Each of these classes has its own QoS parameters such as minimum the throughput requirement and delay jitter constraints $[3,1]$. Table II shows the comparison of these classes.

UGS: This type of service class provides the fixed periodic bandwidth allocation. When the connection is setup, then there is no need to send any other requests. This service is designed for the constant bit rate , real-time traffic such as E1/T1 circuit emulation. The main QoS is the parameters that have maximum sustained rate (MST), maximum latency and tolerated jitter (the maximum delay variation).

ertPS: This service is planned to support VoIP with silence suppression. Here no traffic is sent during silent periods. ertPS service is similar to UGS in that the BS assigned the maximum sustained rate in active mode, but no bandwidth is allocated during the silent period. There is a need to have the BS poll the MS (Mobile Station) during the silent period to determine, if the silent period has ended. The QoS parameters are the similar as those in the UGS.

rtPS: This type of service class is for the variable bit rate (VBR) realtime traffic such as MPEG compressed video. Unlike UGS, rtPS bandwidth requirements vary and so the BS needs to regularly poll each MS to determine what allocations need to be made. The QoS parameters are similar to the UGS but minimum reserved traffic rate and maximum sustained traffic rate need to be specified separately. For the UGS \& the ertPS services, these two parameters are the same, if present .

nrtPS: This service class is for non-real-time VBR traffic with no delay guarantee. Only minimum rate is assured. File Transfer Protocol (FTP) traffic is an e.g of applications using this service class.

BE: Most of data traffic falls into this category. This type of service class guarantees neither delay nor throughput. The bandwidth will be approved to the MS if and only if there is a left-over bandwidth from other classes. In perform most of implementations allow specifying minimum reserved traffic rate and maximum sustained traffic rate even for this class. Note that for non-real-time traffic, traffic priority is also one of the QoS parameters that can differentiate among different connections or subscribers within the same service class. Here Consider the bandwidth request mechanisms for the uplink. UGS, ertPS and rtPS are the instantaneous or real time traffic. In theUGS there is a static allocation. ertPS is the combination of UGS and the rtPS. 
Both UGS and ertPS can reserve the bandwidth during setup. Not like the UGS, ertPS allows all kinds of bandwidth request including contention resolution. rtPS can not take part in contention resolution. For other traffic classes (non realtime traffic), nrtPS and BE, different types of bandwidth requests are allowed such as the piggybacking, bandwidth stealing, unicast polling and contention resolution.

\section{APPLICATION TRAFFIC MODELS FOR THE WIMAX}

WiMAX Forum classifies applications into five categories as shown in Table III. The application class like Multiplayer Interactive Gaming ,VoIP and video conference ,Streaming Media ,Web Browsing and Internet Messaging, Media contents download has its own characteristics such as the bandwidth, in order to assure a good quality of user experience.

\section{TABLE II}

\section{COMPARISON OF WIMAX QOS SERVICE CLASSES}

\begin{tabular}{|l|l|l|}
\hline QoS & Pros & Cons \\
\hline UGS & $\begin{array}{l}\text { UGS No overhead. } \\
\text { Meet guaranteed } \\
\text { latency for real-time } \\
\text { service }\end{array}$ & $\begin{array}{l}\text { Bandwidth may not } \\
\text { be utilized fully since } \\
\text { allocations are } \\
\text { granted regardless of } \\
\text { current need. }\end{array}$ \\
\hline ertPS & $\begin{array}{l}\text { Optimal latency and } \\
\text { data overhead } \\
\text { efficiency }\end{array}$ & $\begin{array}{l}\text { Need to use the } \\
\text { polling method (to } \\
\text { meet delay } \\
\text { guarantee) and a } \\
\text { mechanism to let the } \\
\text { BS know when the } \\
\text { traffic starts during } \\
\text { the silent period. }\end{array}$ \\
\hline rtPS & $\begin{array}{l}\text { Optimal data } \\
\text { transport efficiency }\end{array}$ & $\begin{array}{l}\text { Require the overhead } \\
\text { of bandwidth request } \\
\text { and the polling } \\
\text { latency (to meet the } \\
\text { delay guarantee) }\end{array}$ \\
\hline BE & $\begin{array}{l}\text { BE Provide efficient } \\
\text { service for BE traffic } \\
\text { rate } \\
\text { minimum reserved } \\
\text { service for non-real- }\end{array}$ & $\begin{array}{l}\text { No service guarantee connections } \\
\text { may starve for long } \\
\text { period of time }\end{array}$ \\
\hline NrtPs & $\begin{array}{l}\text { Novide efficient } \\
\text { timith }\end{array}$ \\
\hline
\end{tabular}

\section{HANDOFF MECHANISM}

A special requirement for a mobile device is the ability to change the serving BS if there exists another BS with, for example better link quality in the reach of MS. The handoff in some source referred as handover, is procedure with an intention to switch the network connection access point of MS without data loss or disturbing the existence connection. First, for a handoff to be even possible, one needs to have at least two BSs, the currently serving and the handoff target(s), and an MS within reach of both BSs. The handoff usually is understood as change of serving BS, but it does not necessarily means that BS must be changed. In some case the handoff can occur also within the same BS, through within different channels. This handoff type is called intra-cell handoff, while other option is called inter-cell handoff. Handoffs between different technologies are possible, as already mentioned while discussing the MIH standard. The horizontal handoff was defined to be a handoff within a single technology network, while the vertical handoff changes the network

TABLE II

WIMAX APPLICATIONS

\begin{tabular}{|l|l|l|l|l|}
\hline Classes & $\begin{array}{l}\text { Applicatio } \\
\text { ns }\end{array}$ & \multicolumn{2}{|l|}{$\begin{array}{l}\text { Bandwidth } \\
\text { Guideline }\end{array}$} & $\begin{array}{l}\text { QoS } \\
\text { Classes }\end{array}$ \\
\hline 1 & $\begin{array}{l}\text { Multiplayer } \\
\text { Interactive } \\
\text { Gaming }\end{array}$ & $\begin{array}{l}50 \\
\text { kbps }\end{array}$ & low & $\begin{array}{l}\text { rtPS and } \\
\text { UGS }\end{array}$ \\
\hline 2 & $\begin{array}{l}\text { VoIP and } \\
\text { video } \\
\text { conference }\end{array}$ & $\begin{array}{l}32-64 \\
\text { kbps }\end{array}$ & low & $\begin{array}{l}\text { UGS and } \\
\text { ertPS }\end{array}$ \\
\hline 3 & $\begin{array}{l}\text { Streaming } \\
\text { Media }\end{array}$ & $\begin{array}{l}5 \mathrm{kbps} \\
\text { to 2 } \\
\text { mbps }\end{array}$ & $\begin{array}{l}\text { Low } \\
\text { to high }\end{array}$ & rtPS \\
\hline 4 & $\begin{array}{l}\text { Web } \\
\text { Browsing and } \\
\text { Internet } \\
\text { Messaging }\end{array}$ & $\begin{array}{l}10 \\
\text { kbps } \\
\text { to 2 } \\
\text { Mbps }\end{array}$ & $\begin{array}{l}\text { Moder } \\
\text { ate }\end{array}$ & $\begin{array}{l}\text { BE } \\
\text { Bes and }\end{array}$ \\
\hline 5 & $\begin{array}{l}\text { Media } \\
\text { contents } \\
\text { download }\end{array}$ & $\begin{array}{l}>2 \\
\text { Mbps }\end{array}$ & High & $\begin{array}{l}\text { nrtPS } \\
\text { and BE }\end{array}$ \\
\hline
\end{tabular}

The reason for handoff can be various and here are listed only some of them

1. Single strength is not enough for maintaining proper connection at the edges of the cell

2. BS capacity is full and more traffic is pending

3. Disturbing co channel interference from neighbor cell

4. Behavior of MS changes, for example, for example in case of fast-moving MS suddenly stopping, a large cell size can be adjust to a smaller one with better capacity

5. Faster or cheap network is available ( if vertical handoffs are supported)

Handoff process can be seen as having two stages: (1) Handoff detection, and (2) Handoff execution. Handoff detection includes network discovery and handoff decision. Which kind of handoff metrics should be used and how to 
apply them to make the handoff decision are the main problems in handoff detection. In handoff execution, the mobility management plays an important role. The signaling over head and handoff latency are different in different mobility protocols. To achieve seamless and fast handoff, these two stages should be paid attention to. The time when the handoff decision is made can affect the overall performance of the handoff process such as packet loss. A heavy signaling overhead in handoff management leads to large handoff latency.

\section{PROBLEM FORMULATION OF HANDOFF IN WIMAX USING QOS}

The WiMAX mobile stations need to know the service availability of nearby base stations for immediately pending or future handovers. A list of neighbor sites is broadcast from the serving base station via the Neighbor Advertisement message. The mobile stations will use this as the list of candidate for handovers. The mobile station scans those base stations that determine the best candidate. A missing neighbor condition exists when the valid candidate of neighbor is missing from the neighbor list . During the handoff process sometimes, it's provide the redundant data that also increase the handoff delay and increase its Quality of Service .Some factors degrading the system performance exist in the HO process. Suppose that the MS moves in a certain velocity, if the velocity is low, the network topology architecture may maintain the same in a long time, For a high velocity, the channel condition change frequently, which makes the pre-obtained information become useless? So, during the actual HO process, the neighboring BSs scanning and contention-based ranging operation must be performed, which causes a long HO delay and wireless channel resource waste.

Different radio access technologies present distinct characteristics in terms of mobility management, security support, and QoS . To achieve seamless mobility and end-toend QoS guarantee for the users, these issues should be carefully addressed while developing the in networking and handoff schemes of Wireless mesh networks with various wireless networks. Mesh routers in the WMNs play an important role. 802.16 base station (BS) functions can be integrated into one mesh router. When an Mobile node switches the network interface, only the link type is changed between the MN and mesh routers, and the MN still connects to the same mesh router. In this case, the traditional mobility management such as Mobile IP leads to a large handoff delay with too much signaling cost. Thus to achieve fast and seamless handoff, a new handoff scheme should be considered.

\section{PROPOSED METHODOLOGY}

To decide which queue to service and how much data to transmit, one can use a very simple scheduling technique such as First In First Out (FIFO). This technique is very simple but unfair. A little more complicated scheduling technique is Round Robin (RR). This technique provides the fairness among the users but it may not meet the QoS requirements. Also, the definition of fairness is questionable if the packet size is variable. Here is Channel-unaware schedulers generally assume error-free channel since it makes it easier to prove assurance of QoS. However, in wireless environment where there is a high variability of radio link such as signal attenuation, fading, interference and noise, the channelawareness is important. QoS guarantee is to ensure a minimum throughput guarantee and also to maintain delays that is smaller than a predefined threshold value with a given probability for each user (rtPS and nrtPS).

Power Constraint: The purpose of this class of algorithms is not only to optimize the throughput but also to meet the power constraint. In general, the transmitted power at a MS is limited. As a result, the maximum power allowable is introduced as one of the constraints. Least amount of transmission power is preferred for mobile users due to their limited battery capacities and also to reduce the radio interference. So here we use the algorithm has been proposed a better and fairer approach can be start the allocation with the highest level of modulation scheme. In this scheduling we have to try to find the best subcarriers for the users with the highest number of bits. For this we use the algorithm that likely to fill the un-allocated subcarriers to gain the power reduction. To minimize the transmit power, a horizontal and vertical swapping technique can also be used . in this proposed work we have to combined the methodologies and give the better result . For the improvement of qos we will the tool ns2 to give the better result and analyse it .

\section{CONCLUSION}

In this we summarize about the wimax, its quality of services and how handoff performed in the mesh network. In this we provided an extensive survey of recent scheduling proposals for WiMAX and discussed its issues and design factors. The goals of the scheduling are basically to meet QoS guarantees for all service classes, to maximize the system good put, to maintain the fairness, to minimize power consumption, to have as less a complexity as possible and finally to ensure the system scalability here the procedure it will reduces the signaling overhead and provide the low handoff delay, and try to implement about the power consumption problem for the mobile node and more good handoff performance should be studied for the future.

\section{REFERENCES}

[1] . Qingwen Liu, Student Member, Xin Wang, IEEE, and Georgios B. Giannakis, A Cross-Layer Scheduling Algorithm With QoS Support in Wireless Networks , IEEE 2006

[2] . Harwinder Singh ,Maninder Singh Kamboj "Performance Analysis of QoS in PMP Mode WiMax Networks " International Journal of Computer Volume 3 - No.12, July 2010

[3] Claudio Cicconetti, Luciano Lenzini, and Enzo Mingozz ,"Quality of Service Support in IEEE 802.16 Networks", IEEE Network • March/April 2006

[4] Randeep Bhatia Li (Erran) Li “Throughput Optimization of Wireless Mesh Networks with MIMO Links "Bell Laboratories, Lucent Technologies IEEE infom 2007.

[5] Yongqiang Zhang ," Vertical Handoff between 802.11 and 802.16 Wireless Access Networks “

[6] C. Perkins, UIP Mobility Support for IPv4," RFC 3344, IETF, Aug. 2002.

[7] D. Johnson, C. Perkins, and J. Arkko, MMobility Support in IPv6," IETF, Jun. 2004.

[8] R. Koodli, IFast Handovers for Mobile IPv6," RFC 4068, IETF, Jul. 2005. 
[9]K. Naidoo and R. Sewsunker,University of Kwa-Zulu Natal " 802.11 Mesh Mode Provides Rural Coverage at Low Cost"

[10] About the Wimax Basics, http://www.javvin.com/protocolWiMAX.html

[11] Antti Makelamen, "Analysis of handoff performance in mobile Wimax Network”,Helsinki, Finland. 2007.

[12] An introduction to communication and network , http://en.wikipedia.org/wiki/Communication .

[13] Pranita D. Joshi, Prof. Smita Jangale "Aalysis of VoIP traffic in WiMAX using NS2 simulator "International
Journal of Advanced Research in Computer Science and Electronics Engineering , April 2012

[14] Rohit Talwalkar, “ Analysis of Quality of Service (QoS) in WiMAX Networks," Florida Atlantic University Boca Raton, Florida, May 2008

[15] Rohit Talwalkar, " Analysis of Quality of Service (QoS) in WiMAX Networks," Florida Atlantic University Boca Raton, Florida, May 2008

[16] C. Perkins, IIP Mobility Support for IPv4," RFC 3344 , IETF, Aug. 2002 